\title{
Political participation and social exclusion in later life: What politically active seniors can teach us about barriers to inclusion and retention
}

\author{
By Rodrigo Serrat ${ }^{1}$, Jeni Warburton ${ }^{2}$, Andrea Petriwskyj ${ }^{3} \mathcal{E}$ \\ FELICIANO VILLAR ${ }^{4}$
}

\begin{abstract}
Addressing older people's social exclusion is a major challenge for contemporary societies. However, policies designed to address it have tended to focus on poverty and unemployment. This paper explores the relationship between social exclusion and political participation from the perspective of those already holding responsible roles within seniors' organisations. We aim to highlight the impact of later-life social exclusion in relation to politically active older individuals from two diverse socio-political contexts, Australia and Spain. Participants perceived a range of potential barriers for the inclusion of new members and their own continued

\footnotetext{
${ }^{1}$ Rodrigo Serrat, Department of Cognition, Development, and Educational Psychology, University of Barcelona, Barcelona, Spain

${ }^{2}$ Jeni Warburton, John Richards Initiative, La Trobe University, Wodonga, Victoria, Australia ${ }^{3}$ Andrea Petriwskyj, School of Nursing, Midwifery and Social Work, The University of Queensland, Brisbane, Australia

${ }^{4}$ Feliciano Villar, Department of Cognition, Development, and Educational Psychology,

University of Barcelona, Barcelona, Spain
} 
International Journal of Ageing and Later Life

involvement. These related to practical and resource issues, beliefs and attitudes towards participation, and organisational and contextual issues. Members' views of retention of existing members as well as the recruitment of new members highlight the complexity associated with building the diversity and representativeness that organisations need if they are to represent seniors' views in the policy process.

Keywords: seniors' interest organisations, political participation, barriers, retention, inclusion.

\section{Introduction}

Addressing older people's social exclusion is a major challenge for contemporary societies in view of global population ageing. Yet, social exclusion is "...a complex process that involves the lack or denial of resources, rights, goods and services as people age, and the inability to participate in the normal relationships and activities, available to the majority of people across the varied and multiple domains of society" (Walsh et al. 2017: 83). Despite impacting societal cohesion and individuals' quality of life (Levitas et al. 2007; Scharf \& Keating 2012), older people's social exclusion has been largely overlooked in nations' social policy debates.

Broadly speaking, policies designed to address social exclusion have tended to focus on poverty and unemployment, ignoring many of the broader challenges that face people as they age (Jehoel-Gijsbers \& Vrooman 2007; Warburton et al. 2013). Yet, recent scholarship has suggested that social exclusion should be conceived as a multidimensional concept rather than as a single entity. When applied to older people, social exclusion implies a lack of opportunities for having meaningful relationships and roles in society (Warburton et al. 2013). Social exclusion gains greater significance in later life, when lifelong accumulation of risk can be carried into later life and when older people have fewer pathways to avoid exclusion (Jehoel-Gijsbers \& Vrooman 2007; Warburton et al. 2013). There is growing evidence of old age exclusion associated with factors such as cultural background, location, gender, education and income, and these factors can be compounded by age discrimination or ageist attitudes (Lui et al. 2011). 
Political participation and social exclusion in later life

There is also a growing body of literature focussing on the particular challenges of social exclusion in later life, with a recent landmark review identifying six key domains of old age exclusion. These comprise neighbourhood and community, social relations, services and mobility, material and financial resources, socio-cultural aspects of society and civic participation (Walsh et al. 2017). Of all these domains, however, Walsh et al. (2017) identify civic participation as receiving less overall attention than the other domains.

Civic participation itself is a multidimensional concept and includes a range of potentially diverse activities. According to Walsh et al.'s recent review (2017), the literature includes attention to citizenship, civic participation, general civic activities, volunteering and community responsibility, and voting and political participation. These are important topics, speaking to the ethical rather than utilitarian dimension of social exclusion, as discussed by Nobel Prize winning economist, Amartya Sen, who draws attention to the moral significance of lives valued by individuals (Nussbaum \& Sen 1993). This perspective takes us beyond the economic dimension, and participation in paid work, to explore other aspects of civic participation more pertinent to older people.

Here, we focus on one dimension of civic participation, that of political participation, given the lack of attention to this domain of old age exclusion, and its potential significance to ageing populations. In particular, political participation provides older people with the potential to express agency and achieve integration for themselves (Atkinson 1998; Walsh et al. 2017). We explore a specific and frequently overlooked form of political participation, the involvement in seniors' organisations. Many of these organisations are gaining growing significance in an ageing world and provide key opportunities for older people to redress social exclusion and advocate for seniors' issues (Warburton \& Petriwskyj 2007). There is little evidence reflecting how political participation by seniors is impacting social exclusion, except for some work that has highlighted the challenges of powerlessness and poor advocacy (Raymond \& Grenier 2013).

Thus, this paper explores the broad relationship between social exclusion and political participation from the perspective of those already holding responsible roles within seniors' organisations. We aim to highlight the impact of old age exclusion in relation to two samples of 
International Journal of Ageing and Later Life

politically active older individuals from two diverse socio-political contexts, Australia and Spain, whose ageing policy and welfare contexts are quite different (Warburton \& Jeppsson Grassman 2011). The particular focus of this research is how these individuals view barriers both to their own continued participation as well as to the involvement of others in these organisations. While there is a large research literature on volunteering in later life, there is far less on what stops people from giving their time (Serrat et al. 2018).

Thus, the study explores three research questions: What are the barriers active members of seniors' interest organisations perceive to their own retention (RQ1)? What barriers do these members identify to the inclusion of others (RQ2)? How do participants' views on barriers to inclusion and barriers to retention differ across the two country contexts (RQ3)?

We begin by presenting the key concepts in this study, civic participation and barriers for inclusion and retention, before discussing the sociopolitical contexts of Australia and Spain in more depth

\section{The (Forgotten) Political Dimension of Civic Participation}

Civic participation provides important opportunities for a growing proportion of older people to remain healthy, active and involved (Anderson et al. 2014; Greenfield \& Marks 2004). At the same time, it also enables older people to be more involved in the democratic process and to have their voices heard (Barnes 2005; Fung \& Wright 2001). However, civic participation is a fuzzy concept with no consensus among researchers on its definition (e.g. Ekman \& Amnå 2012). Berger (2009) claimed that the term has been stretched over the last 20 years, as it has been applied to so many different things "... that it clarifies almost nothing" (335). Some have used it to refer to specific activities such as formal volunteering (e.g. Cutler et al. 2011) or a range of political activities (e.g. Burr et al. 2002), while others have used it in a generic way, to refer to any activity - from watching political shows to bowling in leagues - that creates social capital (e.g. Putnam 2000). The limited agreement among scholars on what it means to participate civically has hindered the advancement of research in this area (Berger 2009) as, in words of Van Deth, the study of civic participation has become "... the study of everything" (Van Deth 2001: 4). 
In an attempt to create an operational definition, some researchers have proposed to distinguish between social participation (which includes all the activities connecting individuals to each other, such as volunteering or caregiving) and political participation (which refers to activities aimed at influencing political outcomes) (e.g. Mcbride et al. 2006). A large body of this research was focussed on volunteering by older people, with far less focussing specifically on participation in political activities (for some exceptions see Doyle 2014; Goerres 2009; Nygard \& Jakobsson 2013). However, understanding older people's political participation is key to foster their inclusion in policy-making processes, particularly in the context of ageing populations.

However, political participation is itself further complicated by being multidimensional and including different types of activity. Verba et al. (1995) described political participation as either low investment, such as voting behaviour, or high investment, which requires high levels of effort and commitment and is more likely to be stable over time. Political participation could also be classified according to the degree of institutionalisation, as in institutionalised (Kaase 1999) or conventional (Barrett \& Brunton-Smith 2014) or non-institutionalised or non-conventional forms of political activity.

Much of the previous literature on older people's political participation can be critiqued for its focus on low-investment forms of participation such as voting (e.g. Binstock 2000) as well as to a lesser extent on non-conventional forms of participation such as social-movement organisations (e.g. Narushima 2004). However, high investment and conventional political activities, such as participation in responsible roles within political organisations, have been underexplored in previous research (Serrat \& Villar 2016). Particularly, there is a scarcity of studies addressing older people's political representation and collective action through seniors' interest organisations (Doyle 2014). There are a large number of organisations globally that focus specifically on seniors' interests, including AARP in the United States and the European Federation of Retirees and Elderly People in Europe (FERPA). However, there is a general lack of understanding of what drives and what prevents older people from being included in these organisations. This type of political participation, which includes political advocacy, input into the policy process and 
International Journal of Ageing and Later Life

enabling diverse views, is critical in the contemporary global context if older people's inclusion in civic participation is to be achieved and a diversity of views considered in policy and planning decisions.

\section{Barriers to Political Participation by Older People}

There is an emerging literature on political participation by older people (e.g. Goerres 2009; Nygard \& Jakobsson 2013); however, there are identifiable gaps in knowledge. First, much of the literature focusses on social capital predictors of political participation (e.g. Burr et al. 2002) or on motivations as stimulus for action (e.g. Barnes et al. 2011). However, it is also important to consider what stops people from participating politically in the first place, that is, barriers for inclusion, or what leads people to stop participating, that is, barriers to retention. Barriers to older people's political participation have received far less attention in the literature (Petriwskyj et al. 2017).

Serrat et al. (2017), reviewing the broader literature on barriers to civic participation by older people, proposed to classify the existing evidence into means-related barriers (e.g. health, civic skills, income or available time), motives-related barriers (e.g. lack of interest, disillusionment or a fear of a too demanding involvement) or opportunity context-related barriers (e.g. lack of information about opportunities or organisational problems). However, they highlighted that the type of activity and the context of participation have an important influence on individuals' perceptions of barriers, making it difficult to generalise results to different contexts. The present study specifically addresses barriers to older people's political participation in relation to seniors' interest organisations, a type of political participation which, to our knowledge, has been given very little attention in relation to such barriers.

Second, the literature on barriers matches a tendency in existing evidence to focus on attracting older people, rather than looking at what retains those who already participate. Most studies use samples of older people not involved in political activities (e.g. Gele \& Harsløf 2012) or mixed samples of older people involved and not involved (e.g. Postle et al. 2005). They thus overlook the difference between barriers to inclusion and barriers to retention, which might relate to quite different factors. Yet, while both are important, as Serrat et al. (2017) note, understanding factors 
Political participation and social exclusion in later life

that contribute to retention is even more important to political organisations which have invested in their active members. Their empirical study found that most members of a range of political organisations identified means-related barriers as a potential barrier to continued participation, particularly poor health. However, despite these findings, there is a lack of evidence specifically related to barriers to retention in seniors' interest organisations.

Further, although seniors' interest organisations may employ younger paid staff, they are frequently managed by older people themselves through a number of committees and subcommittees. Active members in responsible roles within these organisations make strategic decisions and are often directly responsible for the inclusion and support of new members. Thus, their views on what prevents others from participating are crucial, as they can affect the way they act as agents for their organisations. They are the experts in their organisations and thus best-placed to judge the hindrances that other older people may confront to become involved. On the contrary, their perceptions on the barriers for the inclusion of new members may contrast with their views on the barriers for their own retention, as their experience of participation may provide them with a more nuanced and deeper understanding of the specific barriers involved in these two processes. Therefore, this study seeks to identify not only what barriers active members of seniors' interest organisations perceive to their own retention (RQ1) but also what barriers they identify to the inclusion of others (RQ2). The third research question is designed to compare findings across the two contexts (RQ3), which are now discussed.

\section{Barriers to Political Participation in Australia and Spain}

Given the nature of the type of political participation discussed here, socio-political context may be an important influence on members' beliefs and practice regarding barriers to inclusion and retention. Thus, our primary research question is explored across two diverse environments with quite distinct social, political and economic contexts. The rationale for this is that up until fairly recently, most literature on political participation emanated from the United States (e.g. Adler et al. 2007; Campbell 2002, 2003), with more recent studies focussed on other parts of the world with 
International Journal of Ageing and Later Life

quite different political and cultural contexts. While there are some studies looking across countries of Europe (Goerres 2007; Melo \& Stockemer 2014), most are single-nation studies, including countries such as Hong Kong (Cheung-Ming Chan \& Cao 2015), Finland (Nygard \& Jakobsson 2013) or the United Kingdom (Barnes et al. 2011). This body of literature generates interesting findings, which highlight the crucial importance of understanding context when interpreting ageing and political participation. A strong rationale for this is provided by social origins theory of Salamon and Anheier (1998), which highlights how the non-profit sector is shaped by different cultural and political contexts. However, almost no studies compare findings across two quite different countries. In the present paper, we seek to contribute to this emerging body of literature by presenting a comparative study across two diverse countries, Spain and Australia.

These two countries experience a growing ageing population. It is expected that the proportion of Australians and Spaniards over 65 will represent $24.5 \%$ and $35.6 \%$, respectively, of the population by 2060 (Australian Bureau of Statistics 2013; Instituto de Mayores y Servicios Sociales 2017). They also share a strong non-profit sector, which channels older people's political participation. However, older people across these two countries have quite different social and cultural backgrounds. These different socio-political experiences across the lifecycle are likely to impact on older people's approaches to political participation (Goerres 2009). While both are now western democratic countries, Australia has experienced a stable political context and long economic boom since the end of World War 2. In contrast, Spain is a much younger democracy, and its older people have experienced a dictatorial past under Franco's regime (Encarnación 2008), which provided little opportunities for their inclusion in civic participation. Although change occurred with democracy in the mid-1970s, those early experiences are likely to be very strong for older Spaniards. Furthermore, in recent years, Spain was deeply affected by the 2008 Global Financial Crisis. Unemployment grew steadily to reach almost 27\% in 2013 (Instituto Nacional de Estadística 2018), and 29\% of Spaniards were at risk of poverty or social exclusion in 2015 (European Commission 2016). The situation of the Spaniards has been aggravated by the politics of austerity encouraged by the European Union and put in place by the conservative government, which included cutbacks in social, 
Political participation and social exclusion in later life

health and educational public services (León \& Pavolini 2014). Older people have been particularly affected by some of these policies, such as increasing retirement age, implementing health co-payment or reducing social services (Deusdad et al. 2016; Legido-Quigley et al. 2013; Serrano et al. 2014). As a result, new social movements and political organisations have arisen as well as others reactivated, including those which are focussed on seniors' issues.

Australian 20th century history has been quite different. As a wageearners' welfare state regime, Australian welfare state is sustained through wage regulation and welfare provided through employment (Warburton 2014). Australians have been provided with a government welfare safety net, whereas in Southern Europe, high levels of informal social relations may act to crowd out civic participation (Warburton \& Jeppsson Grassman 2011). Moreover, Australian baby boomers have a high educational level compared to those of other OECD countries, including Spain (OECD 2017), and have experienced high employment levels during their working lives (Warburton \& Jeppsson Grassman 2011).

The global financial crisis has left Australia relatively unscathed, although in recent decades there have been important changes in incomes, retirement saving and aged care arrangements (Warburton 2014). For example, retirement compulsory superannuation has been recently put in place, which leaves many individuals in a vulnerable position in front of economic crisis and inequitable employment. The ageing population is certainly impacting in government action, and older people in Australia confront a range of political issues. However, compared with their Spanish counterparts, Australian elders have benefited from a relatively secure economic and social background during their youth and adulthood. These experiences are likely to have a different impact on the perspectives of members of seniors' interest organisations in the two countries.

\section{Australian and Spanish Seniors' Interest Organisations}

Spain's associational landscape has been characterised as feeble, as its development did not take place until the death of Franco in 1975 (Montagut 2009). During Franco's dictatorship (1939-1975), there were severe impediments for population participation in civic and political affairs. Public welfare services were extremely limited, and the needs of 
International Journal of Ageing and Later Life

those in extreme poverty depended on catholic organisations that were clearly aligned with the regime (Monzón Campos et al. 2003). A modern welfare state started to be developed in the 1980s, but its construction took place against the background of a very weak civil society (Encarnación 2003). The return of democracy in 1976 supposed an opportunity for the development of new (or illegalised during the regime) civic and political organisations, such as political parties, trade unions, professional or students' associations (Nanetti \& Holguin 2016). Seniors' interest organisations have played a relevant role in this new landscape and are indeed one of the types of organisations most commonly joined by older Spaniards (Rodríguez et al. 2013). Australia has experienced a much more stable associational life during the 20th century. Australian seniors participate at present in a wide range of organisations, including seniors' interest organisations (Warburton \& Jeppsson Grassman 2011).

In both countries, seniors' organisations are very active at the local, state and national policy levels. These organisations tend to have broad agendas and advocate for a range of seniors-related issues such as work and pensions, transport, housing, health and social services, aged care, community services, education or elder abuse, among others. The activities that they undertake are also wide in scope, from offering services and direct support to affiliates, or carrying out lifestyle, educational or social activities, to forming partnerships for consultation and advice with government representatives, or lobbying and campaigning.

Seniors' interest organisations are managed by seniors themselves and have a diversity of governance structures, typically a management committee or board of directors, and a number of divisional subcommittees of specific issues-related subcommittees. Both in Australia and Spain, these organisations are membership-based and rely on external funding resources, including the one provided by government, which has often compromised organisations' sustainability (Warburton \& Petriwskyj 2007).

\section{Methods \\ Participants}

Respondents were active members with designated responsible roles within nine Australian and five Spanish seniors' interest organisations. For the Australian sample, these included six advocacy organisations for 
Political participation and social exclusion in later life

older people's rights, one local government advisory committee, one education organisation and one social and personal interests' organisation. All of these organisations include an advocacy role for seniors. For the Spanish sample, these included one political party for pensioners and four advocacy organisations for older people's rights.

The final sample included 52 participants from across these organisations: 26 from Australia and 26 from Spain. Mean age for the full sample was $73(S D=5.8)$; $65 \%$ were men and $35 \%$ women; and most were married (65\%). Almost one in five reported primary studies or less, $17 \%$ had completed secondary education and $63 \%$ were university or postschool professional training graduates. Participants reported participating in the organisation for a mean of 11.3 years, and devoting an average of 9.3 hours per week to this participation. Australian participants were more educated and reported fewer years of participation and less hours devoted per week to this activity than Spanish respondents. Differences on educational attainment between samples are likely to reflect population-level differences (OECD 2017). Full socio-demographic characteristics and differences between samples are shown in Table 1.

Table 1. Comparative profile of Spanish and Australian samples

\begin{tabular}{lccc}
\hline Variable & $\begin{array}{c}\text { Spanish } \\
\text { sample } \\
(n=26)\end{array}$ & $\begin{array}{c}\text { Australian } \\
\text { sample } \\
(n=26)\end{array}$ & $\begin{array}{c}\text { Total } \\
(N=52)\end{array}$ \\
\hline Age & $\begin{array}{c}73.9 \\
(S D=6.2)\end{array}$ & $\begin{array}{c}72.1 \\
(S D=5.3)\end{array}$ & $\begin{array}{c}73.0 \\
(S D=5.8)\end{array}$ \\
Gender & & & \\
Male & $76.9 \%$ & $53.8 \%$ & $65.4 \%$ \\
Female & $23.1 \%$ & $46.2 \%$ & $34.6 \%$ \\
Marital status & & & \\
Married or the facto partnership & $61.5 \%$ & $72.0 \%$ & $65.4 \%$ \\
Widowed & $15.4 \%$ & $0.0 \%$ & $7.8 \%$ \\
Single & $7.7 \%$ & $12.0 \%$ & $9.8 \%$ \\
Separated or divorced & $15.4 \%$ & $16.0 \%$ & $15.7 \%$ \\
\hline & & & $($ Continued $)$
\end{tabular}


International Journal of Ageing and Later Life

Table 1. (Continued)

\begin{tabular}{lccc}
\hline Variable & $\begin{array}{c}\text { Spanish } \\
\text { sample } \\
(\mathrm{n}=26)\end{array}$ & $\begin{array}{c}\text { Australian } \\
\text { sample } \\
(\mathrm{n}=26)\end{array}$ & $\begin{array}{c}\text { Total } \\
(\mathrm{N}=52)\end{array}$ \\
\hline Education level & & & \\
$\quad$ No formal schooling & $3.8 \%$ & $0.0 \%$ & $1.9 \%$ \\
Primary school education & $34.6 \%$ & $0.0 \%$ & $17.3 \%$ \\
$\quad$ Secondary school education & $34.6 \%$ & $0.0 \%$ & $17.3 \%$ \\
Certificate or professional training/ & $26.9 \%$ & $100.0 \%$ & $63.5 \%$ \\
$\quad$ University degree & & & \\
General self-rated health & $3.8 \%$ & $0.0 \%$ & $1.9 \%$ \\
$\quad$ Very poor/poor & $19.2 \%$ & $11.5 \%$ & $15.4 \%$ \\
Fair & $76.9 \%$ & $88.5 \%$ & $82.7 \%$ \\
Good/excellent & 15.1 & 7.5 & 11.3 \\
Number of years participating & $(S D=9.6)$ & $(S D=8.7)$ & $(S D=9.8)$ \\
& 12.8 & 5.7 & 9.3 \\
Average hours committed per week & $(S D=10.3)$ & $(S D=4.8)$ & $(S D=8.7)$ \\
& & & \\
Internal political efficacy & $38.5 \%$ & $50.0 \%$ & $45.1 \%$ \\
Yes & $7.7 \%$ & $11.5 \%$ & $9.8 \%$ \\
No & $50.0 \%$ & $38.5 \%$ & $45.1 \%$ \\
I don't know & 7.7 & 8.4 & 8.0 \\
Political interest & $(S D=2.2)$ & $(S D=0.9)$ & $(S D=1.7)$ \\
$\quad$ & \multicolumn{2}{c}{} \\
\hline
\end{tabular}

\section{Instruments}

We applied a questionnaire originally designed for the Spanish sample by authors 1 and 4 (RS and FV), and translated for use in the Australian sample by authors 1, 2 and 3 (RS, JW and AP). The questionnaire comprised open-ended questions and incomplete sentences regarding political participation. Results reported here relate to a selection of questions regarding perceived barriers to participation in seniors' organisations. The questionnaire included the following sections:

- Socio-demographic variables: Age, gender, marital status, educational level and self-rated health. 
Political participation and social exclusion in later life

- Participatory characteristics:

- Number of years participating

- Number of hours committed per week

- Internal political efficacy ("Do you believe that your participation will result in changes in government policies?" with response categories "yes", "no" and "I am not sure")

- Importance of participation ("On a scale where 1 means 'no interest at all' and 10 means 'very much interested', how would you rate your interest in politics?").

- Barriers for their own continued involvement: "If at some point in the future you decide to stop participating in your organisation, what could be the reason for this?"

- Barriers for others to become involved: "In your opinion, what are the reasons some people of your age do not get involved in organisations like yours?"

Due to the lack of survey frameworks designed to test the barriers for inclusion and retention of older people in seniors' interest organisations, we chose an exploratory approach using open-ended questions, which allowed us to capture respondents' opinions in their own words.

\section{Procedure}

The first author (RS) of the study collected data from the Spanish sample between February and October 2014, and then authors 1, 2 and 3 (RS, JW and AP, respectively) replicated the study in Australia between June and September 2015. Seniors' interest organisations in Catalonia (Spain) and in Queensland and Victoria (Australia) were approached by email and invited to take part in the study. Organisations which agreed to participate were then asked to distribute the questionnaire to active members through meeting the inclusion criteria for the study: (1) being a member of the board or a committee within the organisation, (2) having participated in the organisation for at least a year prior to data collection and (3) devoting at least 1 hour per week to this activity.

Information about the purpose of the study and the procedure for data collection, instructions to answer the survey, contact details for the researchers, confidentiality and statements of the right to withdraw were 
International Journal of Ageing and Later Life

provided through an information sheet. All participants gave informed consent. The ethics committees of The University of Barcelona and The University of Queensland approved the study. To ensure respondents' anonymity, a unique code was assigned to each participant. These codes (e.g. AUS03_67M), which appear in the results section after each quote, indicate participant's subsample (AUS for Australian, SPA for Spanish) and organisation number (assigned randomly), followed by participants' age and gender ( $\mathrm{M}$ stands for man, $\mathrm{W}$ for woman).

\section{Data Analysis}

We applied content analysis to participants' answers, following a multi-stage process in which ideas or units or meaning were identified and then condensed into categories and sub-categories based on the repetition of ideas or similarity of meaning among units. The analysis was undertaken with the help of ATLAS.ti 7 qualitative analysis software. The process was conducted independently by two researchers to increase the trustworthiness of results. Once they had created a category system, the researchers compared the categories and sub-categories that each of them had identified and discussed their differences until a consensus was reached. Three main categories were identified through the analysis of barriers for continued involvement (retention) and perceived barriers for others to become involved (inclusion) in seniors' interest organisations, each of them including a number of sub-categories: practical and resources issues, beliefs and attitudes towards participation, and organisational and contextual issues.

\section{Results}

Findings are presented in two sections. The first section addresses the barriers to the retention of older participants in seniors' interest organisations (RQ1), and the second the barriers to the inclusion of new participants from the point of view of those who have responsible roles within these organisations (RQ2). Similarities and differences in responses across the Australian and Spanish data sets (RQ3) are commented on in each of the sections. The discussion then focusses on the broader aspects of these questions - what do these findings mean in relation to old age exclusion, particularly for the domain of political participation. 
Political participation and social exclusion in later life

\section{Barriers to Retention}

Analysis of the barriers to continued involvement of participants in seniors' interest organisations identified three overarching categories: practical and resource issues, beliefs and attitudes towards participation, and organisational and contextual issues. These main categories comprised a number of sub-categories, which are detailed below. Some participants mentioned several types of barriers, so their answers were coded into more than one category or sub-category. Table 2 shows a summary of these categories and sub-categories, with their frequency of occurrence by sample, with examples from the two data sets.

Practical and resources issues. The first category related to practical issues or changes in personal resources that would influence participants' future commitment to their organisations. Among them, health or age-related issues appeared as a prevalent sub-category. This included comments such as "If I get too frail/ill" (AUS01_69F) or "... that my health or my age prevent me from participating" (SPA25_81M). Two other sub-categories across both Australian and Spanish data sets were related to family commitments, as in "if my family needs me" (SPA06_80M), or to changes in employment or location, as in "drastic changes in circumstances, such as a change in where I live" (AUS02_75F). However, these two sub-categories were far less commonly mentioned. Finally, one participant stated that the lack of available time would be an obstacle to continue participating in her organisation. Overall, these sub-categories reflect a decrease in means or resources, such as health or available time, or practical issues, such as a change in residential location, which would influence individuals' capacity to continue participating in their organisations.

Beliefs and attitudes towards participation. The second main category related to certain beliefs and attitudes about participation. A common subcategory across both data sets related to a perception that their participation may at some point no longer have an impact in achieving significant changes. For example, an Australian participant said:

if I found that despite best endeavour my participation made absolutely no difference or that the organisation simply gave lip service to advocating and pressing for change. (AUS13_76M) 
International Journal of Ageing and Later Life

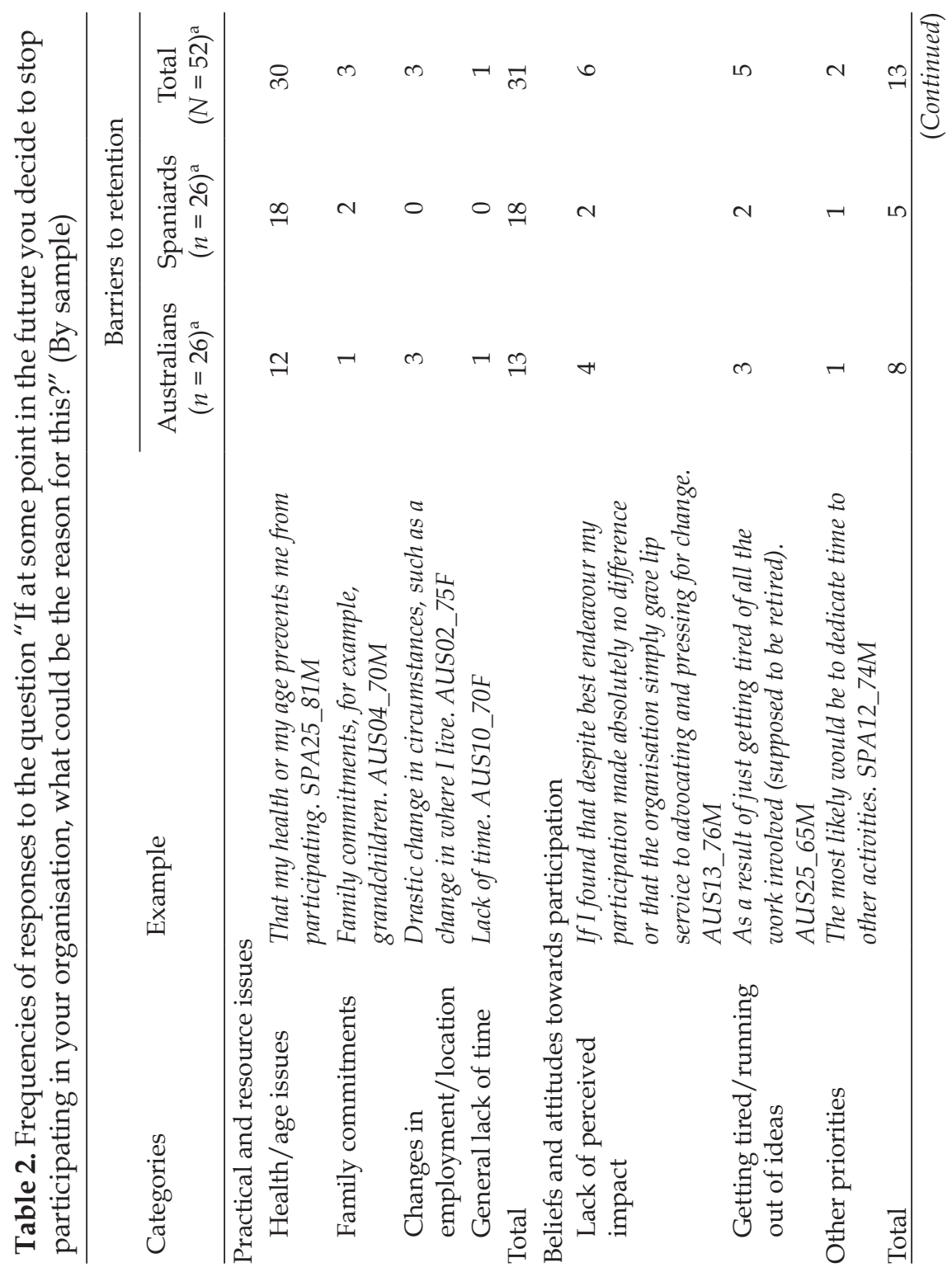


Political participation and social exclusion in later life

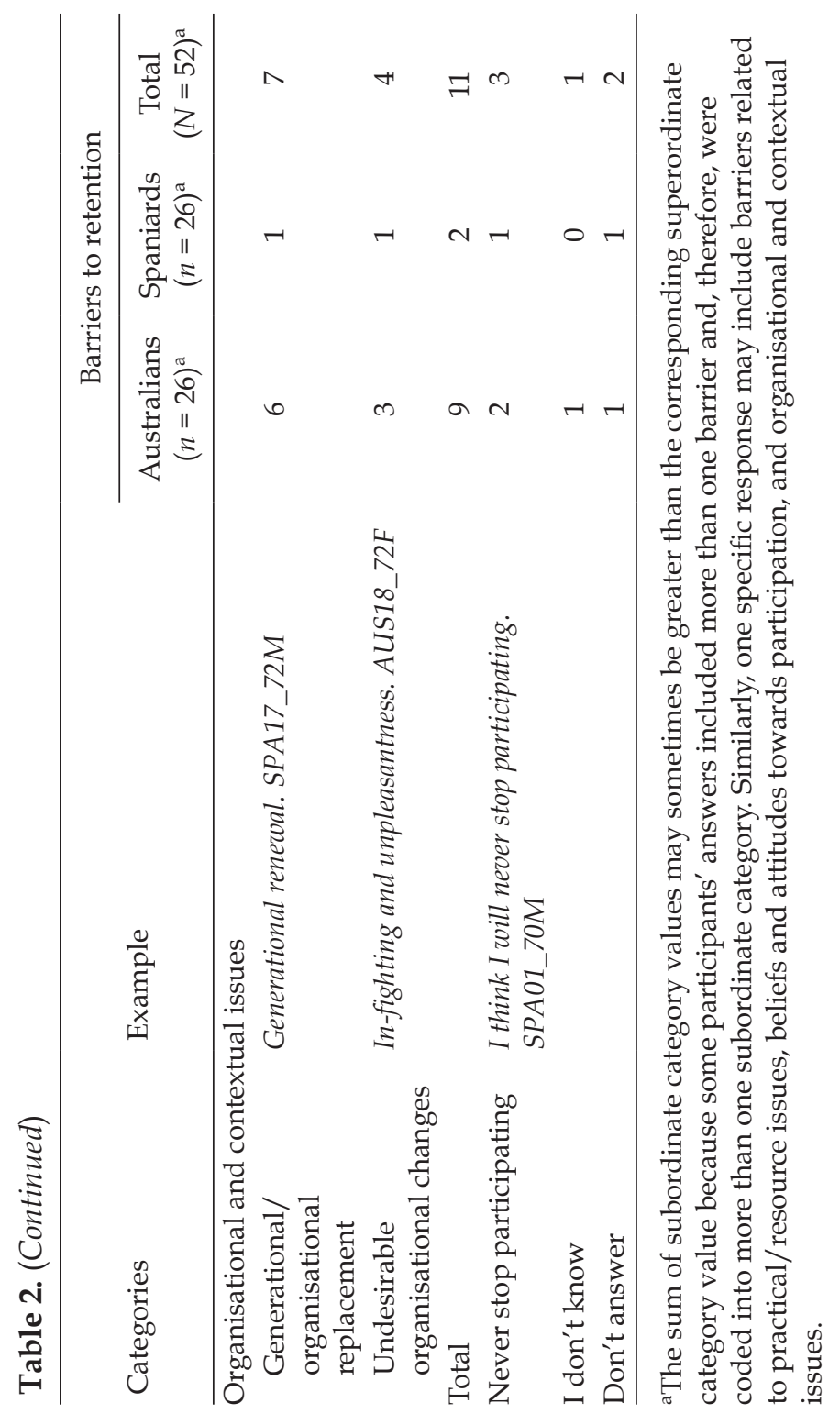


International Journal of Ageing and Later Life

and another stated:

If nothing changes; if [organisation] does not get enough traction to make a difference; if older people continue to be seen as a "burden" by governments then I might consider leaving. The problem is where else could I go to try to influence outcomes? (AUS16_66F)

This was also evident in the Spanish data set, as in "the disappointment of not being able to carry out our projects. If that was the case, I would look for other organizations" (SPA18_74M).

A second related sub-category across both data sets was about getting tired of participating, or running out of useful ideas to contribute to their organisations. Thus, as a participant noted "[I would stop participating]... as a result of just getting tired of all the work involved [supposed to be retired]" (AUS25_65M), with another highlighting "... as a committee member, [I would stop] if I run out of ideas" (AUS01_69F). Finally, two participants stated that time commitments would be a possible reason to give up, as in "the most likely would be to dedicate time to other activities" (SPA12_74M).

Organisational and contextual issues. The third main category, organisational and contextual issues, was noted across both samples, although it was more frequently mentioned in the Australian data set than in the Spanish data set. The first sub-category related to generational replacement and to make room for other voices and points of view within the organisation. For example, an Australian participant stated "the risk of long term occupancy of a position is that change and new ideas are stifled. For me five years on the Board is enough" (AUS09_71M), while another said that the organisation "... needs new eyes" (AUS07_68F). The second sub-category related to experiencing undesirable organisational changes, such as shifts in the organisation's strategic direction or philosophy, or if "the organisation became too partisan political supporting a particular political party" (AUS13_76M), or in "petty politics within the organisation" (AUS25_65M). Overall, these barriers related to externally driven factors that may decrease individuals' opportunities for active involvement with the organisation. Barriers related to organisational and contextual issues were more reported by Australian participants than by Spanish participants.

Never stop participating. It should also be highlighted that three participants did not identify potential barriers, instead stating that they would 
Political participation and social exclusion in later life

not stop participating in their organisations. For instance, an Australian participant said that she was "... not anticipating that [she] would" (AUS20_75F), while a Spanish participant stated that he "... will never stop participating" (SPA01_70M).

\section{Barriers to Inclusion}

With regard to the barriers to the inclusion of new participants, the analysis identified the same three overarching categories that were identified in the analysis of barriers to retention: practical and resource issues, beliefs and attitudes towards participation, and organisational and contextual issues. However, there were important differences in the frequency of mentioning these categories as well as in the sub-categories identified within each of them. Table 3 shows a summary of these categories and sub-categories, with their frequency of occurrence by sample, and examples from the two data sets.

Practical and resource issues. The first category related to the lack of personal resources and practical issues which act as potential barriers for older people to become involved in organisations. Participants across both data sets mentioned health and age-related problems as potential obstacles for other older people, as in "some are too old and tired" (AUS23_81M). Two other sub-categories, mentioned only by Australian respondents, were family commitments, as in "some are trapped in ongoing family caring roles (either grandchildren or very elderly frail parent/s)" (AUS12_65F) and general lack of time, as in "time poor" (AUS07_68F) or "demand of time will be too great" (AUS09_71M). A fourth sub-category identified across both data sets was lack of skills, as in "because they don't have the skills to do it" (SPA15_69M). Finally, one Australian participant stated that transportation would act as a potential barrier for some older people to become involved: "distance to travel - meeting place near public transport" (AUS04_70M).

Beliefs and attitudes towards participation. The second category, related to beliefs and attitudes towards participation, represented the strongest category across both sets of data. A first sub-category highlighted a perceived laziness and apathy among others as a barrier to becoming involved. This sub-category was much stronger in the Spanish data set than in the Australian data set. Spanish participants made comments 
International Journal of Ageing and Later Life

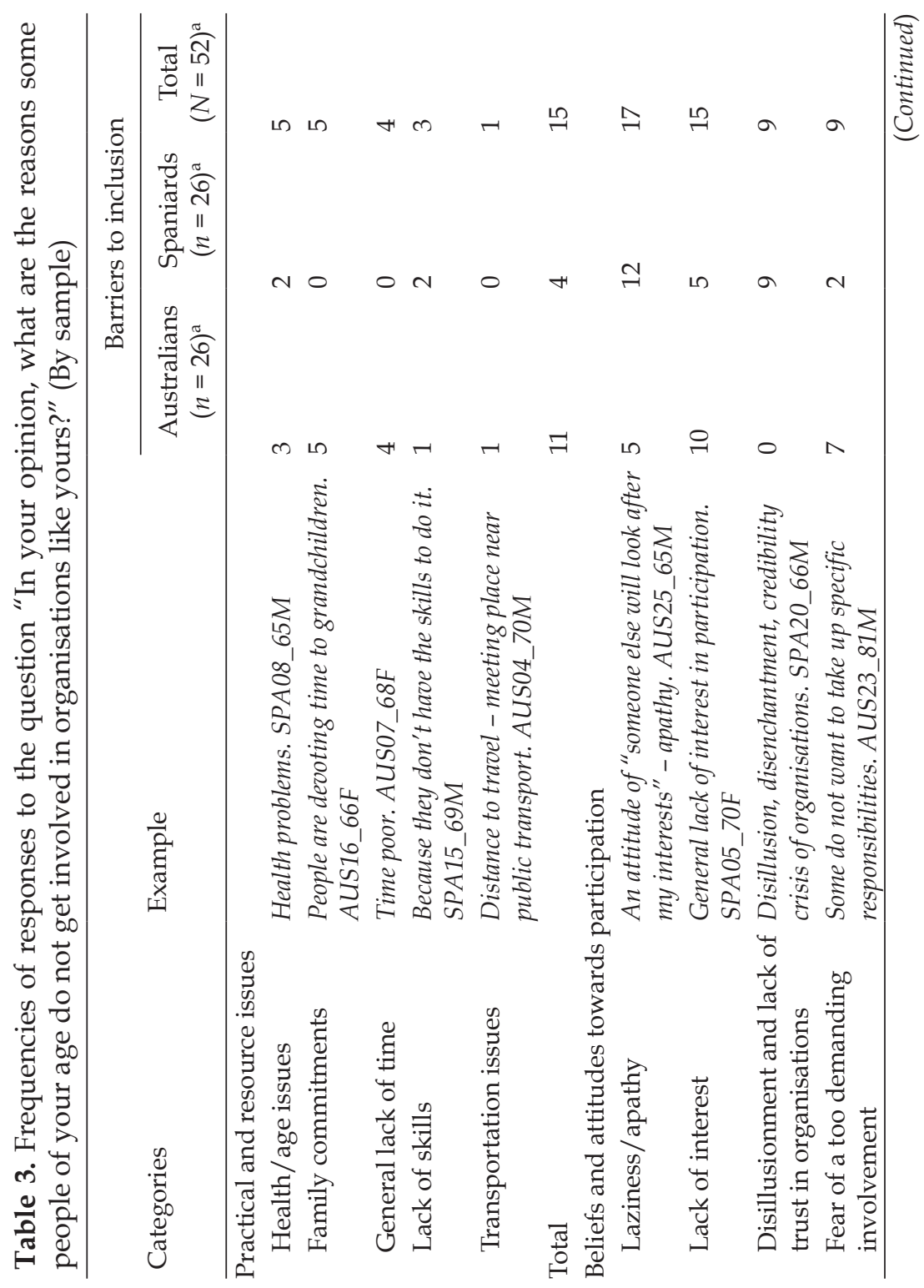


Political participation and social exclusion in later life

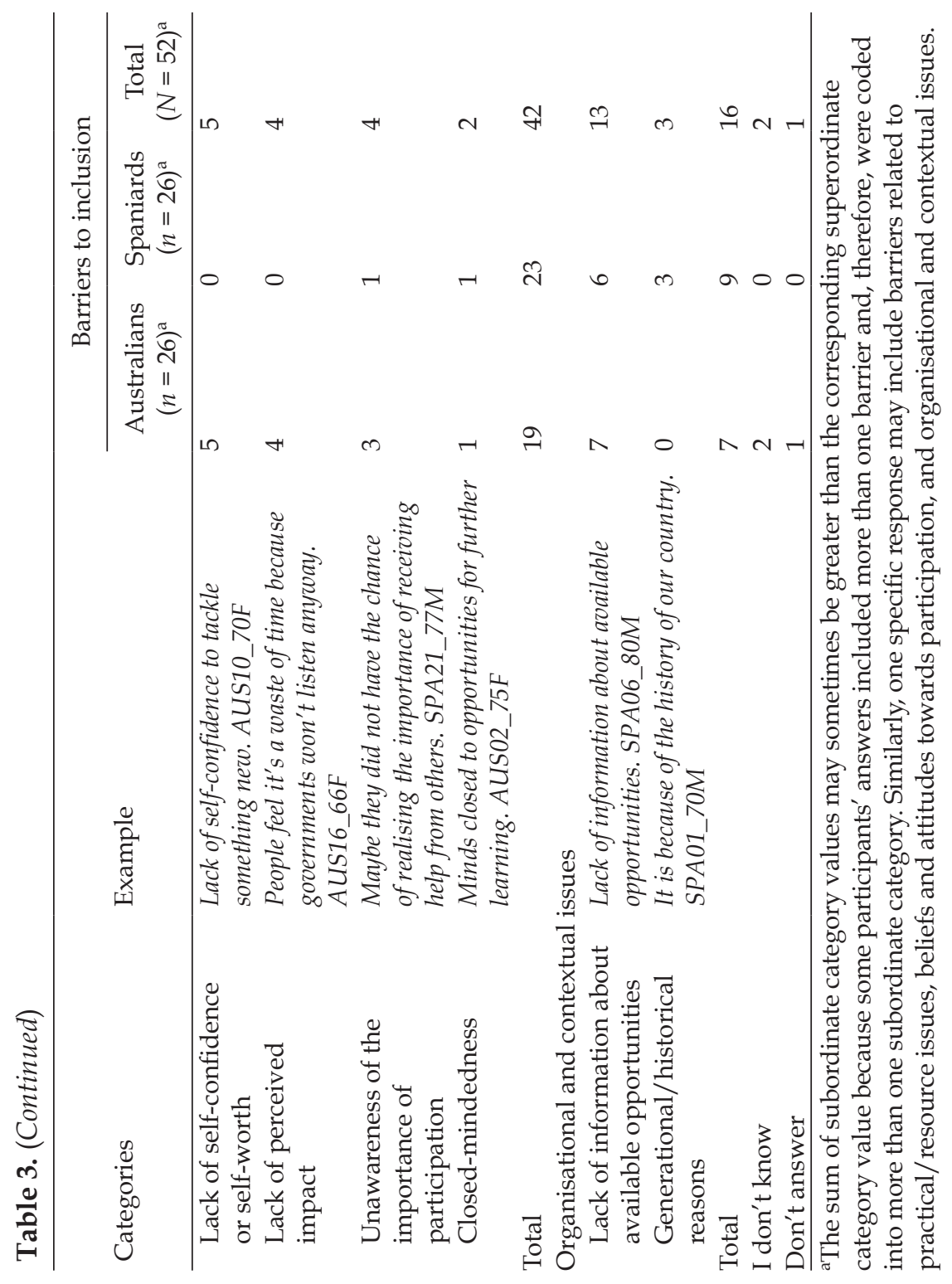


International Journal of Ageing and Later Life

such as "because they lack in character, and they like to waste their time doing other things" (SPA02_81F) or "laziness... disenchantment... they think that they have already participated, that they have done a lot, and now is their time to rest" (SPA19_70M). In addition, a few Australian participants also noted "an attitude of 'someone else will look after my interests' - apathy" (AUS25_65M).

A second sub-category, identified in both data sets, although more frequently mentioned by Australian respondents, related to the lack of interest among older people in actively participating seniors' organisations. A respondent noted "... [they are] just generally not interested in volunteering or they are not interested in meeting at branch levels" (AUS20_75F), while others highlighted that other interests would be more prevalent among older people, as in "... a lot of older people prefer to be involved in more activities that are for enjoyment" (AUS15_71F).

A third sub-category, which was only identified in the Spanish data set, viewed disillusionment and lack of trust in organisations as a barrier for others to become involved. For example, one respondent described it as "... disillusion... disenchantment... crisis of credibility in organisations" (SPA12_66M).

Fear of a too demanding role was also identified as a potential barrier across both data sets. For example, one participant suggested that "some are hesitant to be involved in case they need to be responsible or in a leadership role" (AUS04_70M) and another that "some do not want to take up specific responsibilities" (AUS23_81M).

The fifth and sixth sub-categories were only mentioned by respondents in the Australian data set. The first of these suggested that it was a lack of confidence or self-worth that stopped people, as in "lack of self-confidence to tackle something new" (AUS10_70F), or "many may underestimate their skills and knowledge" (AUS12_65F). The second sub-category proposed that some viewed advocacy through seniors' organisations as useless, as it fails to have a significant impact on governmental decision-making. For example, a participant stated that "people feel it's a waste of time because governments won't listen anyway" (AUS16_66F), and another that "they feel overwhelmed by the issues. They think it is the responsibility of the government and that they cannot change the way the government thinks and acts so why bother" (AUS13_76M). 
Political participation and social exclusion in later life

Finally, participants across both data sets mentioned that some older people were unaware of the importance of advocating for older people's rights through seniors' organisations, as in "lack of awareness about the difference they could make" (AUS10_70F), and two participants highlighted closed-mindedness among older people as a barrier for volunteering for these organisations. One Australian noted that some had their "... minds closed to opportunities for further learning" (AUS02_75F), and a Spanish participant stated "they are closed-minded and it is really difficult to change their opinions" (SPA13_67M).

Organisational and contextual issues. The third main category, organisational and contextual issues, was noted across both samples. A subcategory related to the lack of information about available opportunities, as in "don't know of the organisation and opportunities available to participate" (AUS07_68F), or "some cannot see the connection or options for engagement" (AUS12_65F). A second sub-category, mentioned only by the Spanish respondents, related to generational and historical barriers, as in "it is because of the history of our country" (SPA01_70M), or "the reason is the education they have received" (SPA21_77M).

\section{Discussion}

This study aimed to explore the broad relationship between social exclusion and political participation from the perspective of those already holding responsible roles within seniors' organisations. In particular, we have presented data from two samples of politically active older individuals from two diverse socio-political contexts, Spain and Australia. The particular focus of this research is how these individuals view barriers both to their own continued participation as well as to the involvement of others in these organisations. The intent is to contribute to knowledge about perspectives on exclusion from political participation, as a largely unexplored, but important, dimension of old age exclusion.

Political participation in the form of advocacy provides older people with agency and work towards integration, with seniors' organisations working towards gaining a seat at the policy table (Warburton \& Petriwskyj 2007). It is a critical aspect of redressing old age exclusion and thus is a domain of social exclusion that merits research attention as it is often neglected in favour of other domains such as community or 
International Journal of Ageing and Later Life

services (Walsh et al. 2017). As the population ages, it becomes increasingly important for governments and others to create spaces to hear the voices of older people and ensure that they are included in the democratic process (Barnes 2005; Fung \& Wright 2001). Further, political participation is one dimension of civic participation with implications for older people remaining healthy, active and productive as they age (Anderson et al. 2014; Morrow-Howell et al. 2014). Despite the potential for this form of participation, there is a scarcity of studies addressing this topic (Doyle 2014) and, in particular, a scarcity of studies that look at the barriers (rather than the motivators) to any form of civic participation in later life (Serrat et al. 2017).

Thus, the first two research questions respond to this gap in knowledge by exploring the barriers perceived by active members of seniors' interest organisations to both their own continued involvement as well as the inclusion of new members for the organisation, and to analyse differences on their perceptions of these barriers. These findings are important as they speak to the viewpoints of those already involved in political participation, such as advocacy work, and who are often responsible for the recruitment of more members, ensuring the representativeness and sustainability of their organisations.

These perspectives are context-specific, determined by the political, social and cultural contexts in which they occur. We thus sought to explore these issues across two diverse countries with quite distinct socio-political contexts. This was because, with the exception of a few cross-European studies (Goerres 2009; Melo \& Stockemer 2014), most prior studies in this field are either from the United States (e.g. Campbell 2002, 2003) or another single country (e.g. Barnes et al. 2011). Thus, our third research question aims to address a gap in the literature by adopting a cross-national dimension and exploring differences and similarities across two different contexts, Spain and Australia.

Participants in our study perceived a range of potential barriers for their own continued involvement in seniors' interest organisations (RQ1), as well as for the inclusion of new members in these organisations (RQ2). These related to practical and resource issues, beliefs and attitudes towards participation, and organisational and contextual issues. The first set of findings highlights practical and resource issues, which refer to the availability of resources that are deemed necessary to participate 
Political participation and social exclusion in later life

in seniors' interest organisations, such as health, skills or available time, or practical matters that would affect older people's possibilities of participation, such as changes in employment or location, or transportation issues. There is logic to these aspects as clearly relying on basic personal resources and overcoming practical obstacles provides a common ground for older people both to start and to continue participating in civic life (Serrat et al. 2017).

However, findings show that this type of barrier was more frequently identified as a barrier for retention of existing members rather than a barrier for inclusion of new members. Interestingly, the responses for their own continued involvement was more singularly based on their own health or age issues with fewer other responses. Conversely, respondents noted that to include more members was complex, as responses were more spread across family commitments, lack of time, lack of skills or transport as well as health/age. Thus, it may be that those already active in organisations may have already managed some of these issues and know that they are able to do the work. These findings suggest that if seniors' organisations are to recruit new members, they will need multiple, and demonstrated flexible, approaches to involvement to counter some of these potential concerns.

In particular, seniors' interest organisations seeking to represent older people's voices need to be aware of the diversity of seniors and provide opportunities for participation addressed to individuals with different life-circumstances and skills (Warburton et al. 2007). For example, allowing less time-consuming forms of participation may help to include and retain those with family, work, and other commitments. Organisations need to be socially inclusive, and show how their roles are flexible and achievable, and can involve those who have health issues or are much older. Finally, ride-share opportunities as well as virtual or home-based participation may help to retain those with transportation issues or even those who have changed location. It becomes clear that organisational flexibility is a must in order to overcome participants' practical and resource issues barriers.

The second group of findings suggested that personal beliefs and attitudes towards participation were seen as potential barriers both for retention and recruitment of members in seniors' interest organisations. Here, however, important differences were identified. Failure to achieve 
International Journal of Ageing and Later Life

outcomes or have an impact was common barriers to both recruitment and retention, while other barriers were quite different across these contexts. In terms of retention, participants mentioned that getting tired of the work involved or a change in their personal priorities would stop their involvement. On the contrary, respondents were quite judgemental in terms of why others do not get involved, proposing attitudes and beliefs such as apathy, laziness, lack of interest, lack of self-confidence or closed-mindedness as the main reasons for non-involvement. There were some interesting differences relating to inclusion across the two countries, with Australian respondents more likely to identify a range of different attitudes and beliefs, and the Spanish respondents more likely to identify apathy or disillusionment as the main barriers to inclusion.

Such beliefs and attitudes were seen as being of less significance to retention of active members, who see changes outside their control as the only foreseeable reason to stop. This suggests that attention needs to be paid by organisations for ensuring that existing members perceive that they are making an impact or producing outcomes. However, including new members is more complex and means paying attention to a range of issues, which relate to personal agency and empowerment. From the perspective of participants, these include the need to overcome perceptions of apathy, lack of interest, trust or perceived impact, fear of involvement being too demanding, or that it will be too difficult. While there were differences in responses across the two countries, which we will discuss further below, these data suggest that there is a need for organisations to promote themselves as worthy of involvement, by demonstrating the change they have achieved and showing that involvement is manageable, feasible and worthwhile.

Furthermore, it may be that such perceptions on behalf of those involved are less than helpful in terms of inclusion of a broader and more diverse group of active members. Members need to consider reaching out beyond rather judgemental attitudes and beliefs in order to ensure that seniors' organisations include the views of other, less politically aware or committed individuals and ensure that broad views are included in policy advocacy and organisational processes. Involving a diversity of older people in governance and decision-making has been identified as critical if seniors' organisations are to advocate for issues of real concern for older people. This was initially modelled through a national stakeholder 
Political participation and social exclusion in later life

group, Partnerships for Older People, in the United Kingdom in the late 1990s, and is now increasingly being recognised in the Age-Friendly Community movement (Scharlach \& Lehning 2013). While many of these global initiatives have implications for redressing aspects of social exclusion, there are a few which involve political participation. Some examples include programmes such as the Portland Age-Friendly Cities Project, which have successfully involved a diverse group of older people in the development and rollout of the initiative (Scharlach \& Lehning 2013).

The third group of barriers to either retaining or recruiting new members in the present study included organisational and contextual issues. Generally, there were less responses in this category than in the other two categories for both new and existing members, although there were some particular nuanced differences across the two groups. First, in relation to retention, there were issues related to the fit with the organisation, particularly if there is change within the organisation. Second, in attempting to include new members, there was an identified need to address the lack of information about opportunities for getting involved. This is important to ensure new members are well informed about the organisation and potential for their involvement. This suggests that if old age exclusion is to be addressed in relation to political participation, it means that a broader group of individuals needs to be educated and informed about the intent and focus of these organisations, and their potential role in them.

There were also some differences in findings between the two samples, which suggested the impact of socio-political context, particularly the experience of a dictatorial past by Spanish elders, which may still have effects on their beliefs and attitudes towards political activism. Thus, for example, a few Spanish participants noted generational and historical reasons as a possible barrier for recruitment. Further, findings show that more Australian participants (50\% compared with $38 \%$ ) expressed political efficacy, and hence believed that their participation would impact changes to government policy. This suggests that Australian participants are more likely to have agency and feel that their work can make a difference. They were more likely to suggest that they would give up if they felt that they did not have an impact or experienced undesirable changes. They also suggested that those not involved were unaware that they could in fact make a change through political participation. Spanish respondents, on the contrary, were more 
International Journal of Ageing and Later Life

likely to suggest that disillusionment or lack of trust in organisations might discourage new members. Further, a few Spanish respondents spoke directly of the difficulties of political participation due to the historical context of their country. These findings provide some important indicators of difference in terms of participants' differing perceptions of advocacy and how it can impact policy change. They suggest that somewhat different strategies are required if new members are to be sought in either Australia or Spain. They suggest, for example, that Spanish organisations need to build and demonstrate opportunities for trust to counter disillusionment and apathy, and it may be that this needs to start with existing members, who, while clearly tenacious, need to feel that they can indeed make a difference. Australian organisations, on the contrary, need to promote their outcomes, and clearly demonstrate the importance of involvement and participation, showing how it is in the interests of all to participate. They also need to work to retain their current active members. Across both countries, perceptions of apathy are a concern and need to be countered.

Finally, perceptions of barriers to new members relating to negative beliefs and attitudes deserve special attention both by advocacy organisations and by governments in an ageing world. Policy is undoubtedly much improved if those impacted are allowed a voice and a role in governance and decision-making (Petriwskyj et al. 2012). As noted, there have been some good examples of where this has been attempted. Seniors' organisations such as the ones in this study are critical in promoting and advocating such involvement. In particular, active members in seniors' organisations play a key role as gatekeepers and facilitators for the inclusion of new members. Overcoming their negative perceptions towards those who are not involved may be a first step to help them to build a broader sense of personal agency and empowerment. Existing members have a clear role here if seniors' organisations are to appeal to a broader group of members, specifically by demonstrating the positive aspects of active involvement, as well as enacting positive social inclusionary processes.

To ensure that active political participation can redresses old age exclusion, it is critical that new, more active and positive strategies are adopted to counter feelings that most older people are apathetic and simply do not care or are lazy, as this can lead to gatekeepers who unintentionally devalue or stigmatise those who are unable or do not wish to 
Political participation and social exclusion in later life

participate (Lui et al. 2011). The inclusion of more diverse groups of older people within organisations can help build organisational sustainability and ensure representativeness of the organisation. Furthermore, older people's activism and agency needs to be encouraged if suitable policy outcomes are to be developed that include older people's perspectives and meet their needs. There is potential for positive political participation through the growing Age-Friendly Movement, suggesting that some aspects of old age exclusion can be effectively reduced if more older people are encouraged and supported to participate politically.

\section{Conclusions}

This study has aimed to make a contribution to one particular domain of social exclusion (i.e. civic participation, and specifically, political participation). By exploring the perceptions of active members of seniors' organisations across two diverse contexts, it is possible to extend our understanding of this particular concept of old age exclusion. The study has produced interesting and nuanced findings relating to members' views of both retention of existing members as well as the recruitment of new members, highlighting the complexity associated with building diversity and representativeness in organisations that represent seniors' views in the policy process. Social exclusion here requires attention if such processes are to be truly democratic and effective in an ageing world.

This study has intended to address gaps in knowledge relating to a little researched but important area of old age exclusion. However, it must be acknowledged that this is just one small cross-sectional study comprising 26 participants from diverse seniors' organisations in both the countries. The data represent the perspectives of those who are already active members and their responses are somewhat hypothetical. There is a need now to understand what the actual reasons for these individuals to leave might be, just as it is important to know how those outside these organisations view their own participation. Many of course will be active participants as volunteers, community members or grandparents, and this form of civic participation is also important in an ageing society. Despite this, due to the open-ended methodology, these findings give us insight into important opinions from individuals active in their policy process. 
International Journal of Ageing and Later Life

There is a need for further research to build on this study, particularly as findings suggest differences between including new members and retaining existing ones, as well as differences that exist in contrasting socio-political contexts. Seniors' interest organisations are important in the contemporary ageing context across the world, both in ensuring an ageing voice on issues that impact older people as well as promoting healthy, active and productive ageing. Ensuring capacity to manage this process and being involved in policy directions is core to building sustainable and effective seniors' interest organisations.

\section{Acknowledgments}

This work was supported by Spain's Ministry of Economy and Competitiveness, Reference PSI2016-77864-R. The first author (RS) of this manuscript was supported by a Postdoctoral Fellowship by the University of Barcelona in collaboration with 'La Caixa' Bank Foundation.

The authors wish to thank the participants who generously offered their time during the course of this research.

\section{Corresponding Author}

Rodrigo Serrat, Department of Cognition, Development, and Educational Psychology, University of Barcelona, Passeig de la Vall d'Hebrón 171, ES-08035 Barcelona, Spain. Email: rserrat@ub.edu

\section{References}

Adler, G., Schwartz, J. \& Kuskowski, M. (2007). An exploratory study of older adults' participation in civic action. Clinical Gerontologist 31(2): 65-75. doi: 10.1300/J018v31n02_05

Anderson, N. D., Damianakis, T., Kröger, E., Wagner, L. M., Dawson, D. R., Binns, M. A., Bernstein, S., Caspi, E., Cook, S. L. \& BRAVO Team. (2014). The benefits associated with volunteering among seniors: A critical review and recommendations for future research. Psychological Bulletin 140(6): 1505-1533. doi: 10.1037/a0037610 
Political participation and social exclusion in later life

Atkinson, A. B. (1998). Social Exclusion, Poverty and Unemployment. Case Paper. London: London School of Economics.

Australian Bureau of Statistics. (2013). Population Projections, Australia, 2012 (base) to 2101. Canberra. Available on http://www.abs.gov.au/ ausstats/abs@.nsf/mf/3222.0 (Accessed 26 ${ }^{\text {th }}$ August 2018).

Barnes, M. (2005). The same old process? Older people, participation and deliberation. Ageing and Society 25(2): 245-259. doi: 10.1017/ S0144686X04002508

Barnes, M., Harrison, E. \& Murray, L. (2011). Ageing activists: Who gets involved in older people's forums? Ageing and Society 32(02): 261-280. doi: 10.1017/S0144686X11000328

Barrett, M. \& Brunton-Smith, I. (2014). Political and civic engagement and participation: Towards an integrative perspective. Journal of Civil Society 10(1): 5-28. doi: 10.1080/17448689.2013.871911

Berger, B. (2009). Political theory, political science and the end of civic engagement. Perspectives on Politics 7(2): 335-350. doi: 10.1017/ S153759270909080X

Binstock, R. H. (2000). Older people and voting participation: past and future. The Gerontologist 40(1): 18-31. doi: 10.1093/geront/40.1.18

Burr, J., Caro, F. \& Moorhead, J. (2002). Productive aging and civic participation. Journal of Aging Studies 16(1): 87-105. doi: 10.1016/ S0890-4065(01)00036-6

Campbell, A. (2002). Self-interest, social security, and the distinctive participation patterns of senior citizens. American Political Science Review 96(3): 565-574.

Campbell, A. (2003). Participatory reactions to policy threats: Senior citizens and the defense of social security and medicare. Political Behavior 25(1): 29-49.

Cheung-Ming Chan, A. \& Cao, T. (2015). Age-friendly neighbourhoods as civic participation: Implementation of an active ageing policy in Hong Kong. Journal of Social Work Practice 29(1): 53-68. doi: 10.1080/02650533.2014.993947

Cutler, S. J., Hendricks, J. \& Neill, G. O. (2011). Civic engagement and aging. In R. Binstock \& L. George (eds.), Handbook of Aging and the Social Sciences (7th ed., pp. 221-233). London: Elsevier.

Deusdad, B. A., Comas-d'Argemir, D. \& Dziegielewski, S. F. (2016). Restructuring long-term care in Spain: The impact of the economic 
International Journal of Ageing and Later Life

crisis on social policies and social work practice. Journal of Social Service Research 42(2): 246-262. doi: 10.1080/01488376.2015.1129013

Doyle, M. (2014). The Politics of Old Age: Older People's Interest Organisations and Collective Action in Ireland. Manchester: Manchester University Press.

Ekman, J. \& Amnå, E. (2012). Political participation and civic engagement: Towards a new typology. Human Affairs 22(3): 283-300. doi: 10.2478/ s13374-012-0024-1

Encarnación, O. M. (2003). The myth of civil society: Social capital and democratic consolidation in Spain and Brazil. New York: Palgrave.

Encarnación, O. M. (2008). Spanish politics: Democracy after dictatorship. Cambridge: Polity Press.

European Commission. (2016). People at risk of poverty or social exclusion. Brussels. Available on http://ec.europa.eu/eurostat/ statistics-explained/index.php/People_at_risk_of_poverty_or_ social_exclusion (Accessed $26^{\text {th }}$ August 2018).

Fung, A. \& Wright, E. O. (2001). Deepening democracy: Innovations in empowered participatory governance. Politics \& Society 29(1): 5-41. doi: 10.1521 / siso.2006.70.4.566

Gele, A. A. \& Harsløf, I. (2012). Barriers and facilitators to civic engagement among elderly African immigrants in Oslo. Journal Immigrant Minority Health 14: 166-174. doi: 10.1007/s10903-010-9423-8

Goerres, A. (2007). Why are older people more likely to vote? The impact of ageing on electoral turnout in Europe. British Journal of Politics and International Relations 9(1): 90-121. doi: 10.1111/j.1467-856X.2006.00243.x

Goerres, A. (2009). The Political Participation of Older People in Europe: The Greying of our Democracies. Basingstoke: Palgrave Macmillan.

Greenfield, E. \& Marks, N. (2004). Formal volunteering as a protective factor for older adults' psychological well-being. The Journals of Gerontology. Series B, Psychological Sciences and Social Sciences 59(5): S258-S264. doi: 10.1093/geronb/59.5.S258

Instituto de Mayores y Servicios Sociales. (2017). Informe 2016: Las Personas Mayores en España. Datos Estadísticos Estatales y por Comunidades Autónomas. Madrid. Available on http://www.imserso. es/InterPresent1/groups/imserso/documents/binario/112017001_ informe-2016-persona.pdf (Accessed $26^{\text {th }}$ August 2018). 
Political participation and social exclusion in later life

Instituto Nacional de Estadística. (2018). Encuesta de Población Activa. Madrid. Available on http://www.ine.es/prensa/epa_tabla.htm (Accessed 26 $6^{\text {th }}$ August 2018).

Jehoel-Gijsbers, G. \& Vrooman, C. (2007). Social Exclusion of the Elderly: A Comparative Study of EU Member States. Brussels: Centre for European Policy Studies, European Network of Policy Research Institutes.

Kaase, M. (1999). Interpersonal trust, political trust and non-institutionalised political participation in Western Europe. West European Politics 22(3): 1-21. doi: 10.1080/01402389908425313

Legido-Quigley, H., Otero, L., la Parra, D., Alvarez-Dardet, C., MartinMoreno, J. M. \& McKee, M. (2013). Will austerity cuts dismantle the Spanish healthcare system? BMJ 346: 1-5. doi: 10.1136/ bmj.f2363

León, M. \& Pavolini, E. (2014). 'Social investment' or back to 'familism': The impact of the economic crisis on family and care policies in Italy and Spain. South European Society \& Politics 19(3): 353-369. doi: 10.1080/13608746.2014.948603

Levitas, R., Pantazis, C., Fahmy, E., Gordon, D., Lloyd, E. \& Patsios, D. (2007). The Multi-Dimensional Analysis of Social Exclusion. London: University of Bristol, Bristol. doi: 10.1177/1744987110370529

Lui, C-W., Warburton, J., Winterton, R. \& Bartlett, H. (2011). Critical reflections on a social inclusion approach for an ageing Australia. Australian Social Work 64(3): 1-17.

Mcbride, A. M., Sherraden, M. S. \& Pritzker, S. (2006). Civic engagement among low-income and low-wealth families: In their words. Family Relations 55(2): 152-162. doi: 10.1111/j.1741-3729.2006.00336.x

Melo, D. F. \& Stockemer, D. (2014). Age and political participation in Germany, France and the UK: A comparative analysis. Comparative European Politics 12(1): 33-53. doi: 10.1057/cep.2012.31

Montagut, T. (2009). The third sector and policy process in Spain: The emergence of a new policy player. In J. Kendall (ed.), Handbook on Third Sector Policy in Europe: Multi-level Processes and Organized Civil Society (pp. 119-139). Northampton: Edward Elgar Publishing.

Monzón Campos, J. L., Sajardo Moreno, A. \& Serra Yoldi, I. (2003). Informes nacionales: España. In J. L. Monzón Campos, D. Demoustier, A. Sajardo Moreno \& I. Serra Yoldi (eds.), El tercer sector no lucrativo en el Mediterráneo (pp. 23-99). Valencia: Centro Internacional de Investigación e Información sobre la Economía Pública, Social y Cooperativa. 
International Journal of Ageing and Later Life

Morrow-Howell, N., Lee, Y., Mccrary, S., \& McBride, A. (2014). Volunteering as a pathway to productive and social engagement among older adults. Health Education \& Behavior 41(1): 84-90. doi: $10.1177 / 1090198114540463$

Nanetti, R. \& Holguin, C. (2016). Social capital in development planning: Linking the actors. New York: Palgrave.

Narushima, M. (2004). A gaggle of raging grannies: The empowerment of older Canadian women through social activism. International Journal of Lifelong Education 23(1): 23-42. doi: 10.1080/0260137032000172042

Nussbaum, M. \& Sen, A. (1993). The quality of life. New York: Oxford University Press.

Nygard, M. \& Jakobsson, G. (2013). Senior citizens and political participation - Evidence from a Finnish regional study. Ageing \& Society 33(1): 159-180. doi: 10.1017/S0144686X11001139

OECD. (2017). Education at a Glance 2017. OECD Indicators. Paris. Available on http://www.oecd.org/education/education-at-a-glance-19991487. htm (Accessed 26 $6^{\text {th }}$ August 2018).

Petriwskyj, A., Serrat, R., Warburton, J., Everingham, J. \& Cuthill, M. (2017). Barriers to older people's participation in local governance: The impact of diversity. Educational Gerontology 43(5): 259-275. doi: 10.1080/03601277.2017.1293391

Petriwskyj, A., Warburton, J., Everingham, J., \& Cuthill, M. (2012). Diversity and inclusion in local governance: An Australian study of seniors' participation. Journal of Aging Studies 26(2): 182-191. doi: 10.1016/j.jaging.2011.12.003

Postle, K., Wright, P. \& Beresford, P. (2005). Older people's participation in political activity - making their voices heard: A potential support role for welfare professionals in countering ageism and social exclusion. Practice 17(3): 173-189. doi: 10.1080/09503150500285123

Putnam, R. D. (2000). Bowling Alone: The Collapse and Revival of American Community. New York: Simon and Schuster.

Raymond, E. \& Grenier, A. (2013). Participation in policy discourse: New forms of exclusion for seniors with disabilities. Canadian Journal of Ageing 32: 117-129.

Rodríguez, G., Rodríguez, P., Castejón, P. \& Morán, E. (2013). Las Personas Mayores que Vienen: Autonomía, Solidaridad y Participación Social. Madrid: Fundación Pilares. 
Political participation and social exclusion in later life

Salamon, L. M. \& Anheier, H. K. (1998). Social origins of civil society: Explaining the nonprofit sector cross-nationally. Voluntas: International Journal of Voluntary and Nonprofit Organizations 9(3): 213-248. doi: 10.1023/a:1022058200985

Scharf, T. \& Keating, N. (2012). Social exclusion in later life: A global challenge. In T. Scharf \& N. Keatin (eds.), From Exclusion to Inclusion in Old Age: A Global Challenge (pp. 1-16). Bristol: The Policy Press.

Scharlach, A. \& Lehning, A. (2013). Ageing friendly communities and social inclusion in the United States of America. Ageing and Society 33(1): 110-136.

Serrano, J. P., Latorre, J. M. \& Gatz, M. (2014). Spain: Promoting the welfare of older adults in the context of population aging. Gerontologist 54(5): 733-740. doi: 10.1093/geront/gnu010

Serrat, R., Petriwskyj, A., Villar, F. \& Warburton, J. (2017). Barriers to the retention of older participants in political organisations: Evidence from Spain. Ageing \& Society 37(3): 581-606. doi: 10.1017/S0144686X15001361

Serrat, R. \& Villar, F. (2016). Older people's motivations to engage in political organizations: Evidence from a Catalan Study. VOLUNTAS: International Journal of Voluntary and Nonprofit Organizations 27(3): 1385-1402. doi: 10.1007/s11266-016-9710-7

Serrat, R., Villar, F. \& Celdrán, M. (2018). Encouraging older people to continue participating in civil society organizations: A systematic review and conceptual framework. In M. Coetzee, N. Ferreira \& I. Porgieter, Psychology of Retention: Contemporary Theory, Research, and Practice (pp. 1-18). Basel: Springer.

Van Deth, J. W. (2001), 'Studying political participation. Towards a theory of everything?'. Paper presented at the Joint Session of Workshops of the European Consortium for Political Research, 6-11 April 2001, Grenoble, France.

Verba, S., Scholzman, K., \& Brady, H. (1995). Voice and equality: Civic voluntarism in American politics. Cambridge: Harvard University Press.

Walsh, K., Scharf, T. \& Keating, N. (2017). Social exclusion of older persons: A scoping review and conceptual framework. European Journal of Ageing 14(1): 81-98. doi: 10.1007/s10433-016-0398-8

Warburton, J., Paynter, J., \& Petriwskyj, A. (2007). Volunteering as a productive aging activity: Incentives and barriers to volunteering by Australian seniors. Journal of Applied Gerontology 26(4): 333-354. doi: $10.1177 / 0733464807304568$ 
International Journal of Ageing and Later Life

Warburton, J. (2014). Ageing and social policy in Australia. In S. Harper \& K. Hamblin (eds.), International Handbook of Ageing and Public Polic (pp. 301-317). Chelternham: Edward Elgar Publishing.

Warburton, J. \& Jeppsson Grassman, E. (2011). Variations in older people's social and productive ageing activities across different social welfare regimes. International Journal of Social Welfare 20(2): 180-191. doi: 10.1111/j.1468-2397.2009.00691.x

Warburton, J., Ng, S.-H. \& Shardlow, S. (2013). Social inclusion in an ageing world. Introduction to the special issue. Ageing and Society 33(1): $1-15$.

Warburton, J. \& Petriwskyj, A. (2007). Who speaks for Australia's seniors?: Policy partnerships and older Australians. Just Policy: A Journal of Australian Social Policy 45: 38-42. 